Año 13.

Revista de Investigación

Núm. 33

Académica sin Frontera

https://revistainvestigacionacademicasinfrontera.unison.mx/index.php/RDIASF

Recibido el 17 de junio de 2020. Dictaminado mediante arbitraje favorablemente 30 de noviembre de 2020.

\title{
TEORÍA DEL DELITO Y TEORÍA DEL CASO
}

\section{THEORY OF CRIME AND THEORY OF CASE}

\author{
Jorge Luis Arellano Cruz \\ https://orcid.org/0000-0002-8735-5060 \\ Carmen Virginia Mendivil Cortez \\ https://orcid.org/0000-0003-0803-5518 \\ Universidad Estatal de Sonora
}

\section{Resumen}

El crimen vino aunado a la humanidad, si nos remontamos al primer hecho delictivo que se vivió en el planeta tierra, el presente trabajo busca realizar un recuento breve de la evolución y los conceptos principales que se relacionan con la dogmática penal, explicar en primera instancia que es el delito, para posteriormente puntualizar y entender el porqué de la aplicación de la teoría del delito en la teoría del caso.

Cabe señalar que estas teorías se encuentran hoy más vigentes que nunca puesto que la parte medular o sustantiva del derecho penal no se afectó con la implementación del nuevo sistema penal acusatorio, de ahí que el argumento relacionado con que la teoría del delito se requiera solo en la audiencia de juicio resulte ser una completa mentira, misma que explicaremos en el presente trabajo, como son de gran importancia estas dos teorías, pero como todo parte de la teoría del delito.

Se pretende establecer la importancia de la aplicación de la Teoría del Delito a la Teoría del Caso, es decir en qué medida se interrelacionan una y otra en el curso 
Año 13.

Revista de Investigación

Núm. 33

Académica sin Frontera

https://revistainvestigacionacademicasinfrontera.unison.mx/index.php/RDIASF

Recibido el 17 de junio de 2020. Dictaminado mediante arbitraje favorablemente 30 de noviembre de 2020.

del proceso penal acusatorio, que eventualmente permite dar soluciones legales a casos concretos, además de ser un modesto aporte respecto del conocimiento de la teoría del delito aplicada a la teoría del caso.

Palabras Clave: Delito, Teoría del delito, Teoría del caso, Ley.

\begin{abstract}
The crime came together with humanity, if we go back to the first criminal act that was lived on planet earth, this work seeks to make a brief account of the evolution and the main concepts that are related to criminal dogmatics, explain in the first instance which is crime, to later point out and understand the reason for the application of the theory of crime in the theory of the case.

It should be noted that these theories are more valid today than ever since the core or substantive part of criminal law was not affected by the implementation of the new accusatory criminal system, hence the argument that the theory of crime is required only in the trial hearing turns out to be a complete lie, which we will explain in the present work, how these two theories are of great importance, but like all parts of the theory of crime.

It is intended to establish the importance of the application of the Theory of Crime to the Theory of the Case, that is to say to what extent they are interrelated in the course of the accusatory criminal process, which eventually allows legal solutions to specific cases, in addition to being a modest contribution regarding knowledge of crime theory applied to case theory.

Key Words: Crime, Crime theory, Case theory, Law.
\end{abstract}


Revista de Investigación

Año 13.

Académica sin Frontera

Núm. 33

ISSN: 2007-8870

https://revistainvestigacionacademicasinfrontera.unison.mx/index.php/RDIASF

Recibido el 17 de junio de 2020. Dictaminado mediante arbitraje favorablemente 30 de noviembre de 2020.

\section{Introducción}

El crimen vino aunado a la humanidad, si nos remontamos al primer hecho delictivo que se vivió en el planeta tierra, la Biblia nos dice en Génesis 4:8 (p. 17, Valera: 2009), "porque Dios aceptó a Abel y su ofrenda, pero rechazó a Caín y la suya", donde el primer hombre que descubrió el poder destructivo de la ira, fue Caín, que mató a su hermano Abel.

El presente trabajo busca realizar un recuento breve de la evolución y los conceptos principales que se relacionan con la dogmática penal, explicar en primera instancia que es el delito, para posteriormente puntualizar y entender el porqué de la aplicación de la teoría del delito en la teoría del caso, cabe señalar que estas teorías se encuentran hoy más vigentes que nunca puesto que la parte medular o sustantiva del derecho penal no se afectó con la implementación del nuevo sistema penal acusatorio, de ahí que el argumento relacionado con que la teoría del delito se requiera solo en la audiencia de juicio resulte ser una completa mentira, misma que explicaremos en el presente trabajo, como son de gran importancia estas dos teorías, pero como todo parte de la teoría del delito.

El delito siempre ha existido, con mayor o menor recurrencia, con mayores o menores hechos de sangre, por fines de honor, de lucro, o inclusive por necesidad. Las sanciones de las conductas que con el tiempo se han tipificado por el legislativo, como delitos. En los primeros años de la humanidad eran conceptualizadas como pecado, lo cual representaba una ofensa, no sólo a la sociedad, sino preponderantemente a Dios, y en consecuencia existió la necesidad de espiar los pecados mediante la imposición de diversas penas, vocablo que prevalece en la 
Revista de Investigación

Año 13.

Académica sin Frontera

Núm. 33

ISSN: 2007-8870

https://revistainvestigacionacademicasinfrontera.unison.mx/index.php/RDIASF

Recibido el 17 de junio de 2020. Dictaminado mediante arbitraje favorablemente 30 de noviembre de 2020.

actualidad, pues justamente se habla de pena privativa de libertad y penas pecuniarias.

Con el nacimiento del Estado moderno, la facultad de sancionar los delitos queda en manos del Estado, mismo que se encargaría de crear todas las herramientas para castigar los hechos delictivos, así como para evitar que estos se siguieran cometiendo.

En otro sentido, la teoría del delito constituye a la vez un límite para el poder punitivo del Estado, al asegurar que la imposición de una sanción penal no pueda llevarse a cabo, por todo ello, esta teoría deviene también en una importante herramienta metodológica y técnica al servicio de la teoría del caso.

En este trabajo se pretende establecer la importancia de la aplicación de la Teoría del Delito a la Teoría del Caso, es decir en qué medida se interrelacionan una y otra en el curso del proceso penal acusatorio, que eventualmente permite dar soluciones legales a casos concretos, además de ser un modesto aporte respecto del conocimiento de la teoría del delito aplicada a la teoría del caso, seguro quedados lejos de un análisis completo y profundo sobre la temática, sin embargo esperamos que sea una modesta aportación al conocimiento jurídico-penal y reúna los elementos suficientes para la evaluación de la prueba escrita, aprobada por el jurado en la convocatoria de marras.

\section{Teoría del delito}


Año 13.

Académica sin Frontera

Núm. 33

ISSN: 2007-8870

https://revistainvestigacionacademicasinfrontera.unison.mx/index.php/RDIASF

Recibido el 17 de junio de 2020. Dictaminado mediante arbitraje favorablemente 30 de noviembre de 2020.

La Teoría del Delito constituye una herramienta básica para la parte acusadora y la defensa, en virtud que permite, saber cuándo un hecho puede ser considerado o no delito, grado de ejecución, formas de intervención, naturaleza de la conducta, razón de mérito justificante $o$ atenuante y las consecuencias jurídicas a que se haría acreedor su autor o participe.

Esta definición que para mí ver es la más adecuada y veraz (Valadez: 2017), donde de forma amplia nos da una visión general de esta teoría ya que ella se ocupa del estudio de las características que debe tener cualquier hecho para que pueda ser considerado como delito, pues conforme al principio de la legalidad (nullum crimen, nulla poena sine lege), una conducta solo podrá ser delictiva si está prevista como tal en la ley penal. Sin embargo, los hechos que se manifiestan en la realidad son tan complejos y diversos que no siempre resulta fácil determinar si constituyen o no delito; en otras ocasiones, el hecho no está descrito exactamente en la ley, o más aun, la ley presenta problemas de ambigüedad o vaguedad.

Es por ello la importancia que tiene el conocer esta teoría ya que nos proporciona las herramientas teóricas y metodológicas para resolver, en forma coherente y racional, el conflicto de intereses sometidos a la potestad jurisdiccional penal. Permite "verificar" si están dados los presupuestos para requerir de la agencia judicial una respuesta que habilita el ejercicio del poder punitivo".

Ante este situación, el autor antes citado nos hace mención que esta teoría nos brinda las herramientas necesarias para racionalizar el poder punitivo estatal y generar mayor certeza jurídica al gobernado; determina las fronteras mínimas entre lo prohibido y lo penado por el Derecho Penal (Amuchategui: 2012), es decir, "Ios elementos que deben concurrir, como mínimo y con carácter general, para que algo sea jurídico-penalmente prohibible y punible". 
Año 13.

Revista de Investigación

Núm. 33

Académica sin Frontera

https://revistainvestigacionacademicasinfrontera.unison.mx/index.php/RDIASF

Recibido el 17 de junio de 2020. Dictaminado mediante arbitraje favorablemente 30 de noviembre de 2020.

En este sentido, el cometido fundamental de la Teoría del Delito es el estudio de las características comunes o constantes que debe reunir cualquier acción u omisión humana. Susceptible de sanción, teniendo como punto de partida y límite un determinado marco legal, pues, finalmente, es una Teoría de la Ley. Pero también se le atribuye la función de procurar a través del método dogmático, el conocimiento de la conducta punible en su conjunto para elaborar un sistema coherente, racional, objetivo y armónico del Derecho Penal, que sirve de modelo de análisis que facilite a los operadores del sistema penal, el planteo y la decisión de los casos que se le presenten.

\subsection{Delito.}

Pero como fue que llegamos al punto de que la dogmática penal la denominara "Teoría del Delito", partiremos por definir el concepto de Delito, que es la Conducta típica, antijurídica y culpable constitutiva de infracción penal. Eugenio Cuello Calón (Cuello: 1937), define el delito como una acción antijurídica, típica, culpable y sancionada con una pena.

El código Penal del Estado de Sonora (H. Congreso del Estado de Sonora: 2019), define el delito en su artículo 5 de la siguiente manera:

ARTICULO 50.- Delito es la acción u omisión típica, antijurídica y culpable sancionada por las leyes penales.

\subsection{Principales escuelas de la teoría del delito.}


Año 13.

Académica sin Frontera

Núm. 33

ISSN: 2007-8870

https://revistainvestigacionacademicasinfrontera.unison.mx/index.php/RDIASF

Recibido el 17 de junio de 2020. Dictaminado mediante arbitraje favorablemente 30 de noviembre de 2020.

Luis Rodríguez Manzanera (Rodríguez: 2020), considera que delito es la acción u omisión que castigan las leyes penales, es la conducta definida por la ley, ahora bien direccionándonos sobre la teoría del delito lo consiguiente por definir seria el derecho penal, este se conforma de un conjunto de normas elaboradas por el Estado, mismas que contienen un supuesto de hecho conocido como "delito", mencionado y definido anteriormente, y su consecuencia jurídica como sanción es la pena.

Siguiendo un orden cronológico es importante plasmar en este trabajo las principales escuelas que dieron pie a esta teoría, la tarea de determinar cuándo un hecho es un delito no ha resultado fácil, tan es así que no fue hasta el siglo XVIII que se concretizo esa tarea desde un punto de vista científico; en ese aspecto fue Beccaria a quien corresponde la primera elaboración moderna de la teoría del delito, ello como producto de la filosofía política del iluminismo europeo, en el marco conceptual del Estado liberal y del derecho, consecuencia de las ideas del contrato social y la división de poderes, esa ardua tarea se ha reflejado en la evolución del contenido epistemológico del derecho penal.

Es así, en virtud del avance que ha tenido la teoría del delito se han distinguido diversos sistemas con relación a como se ha interpretado, para ello se cuenta con un sistema clásico, neoclásico, final de acción y por ultimo funcionalista o finalista. Gracias a todo lo anterior citado se dio un gran avance en esta teoría, se representa el contenido o la extensión del tipo penal ya que para el sistema clásico el tipo penal se encontraba conformado solo por elementos objetivos, por su parte para el sistema neoclásico, el tipo penal se distinguía entre tipo objetivo que incluía los elementos objetivos y normativos, y el tipo subjetivo que refería a los elementos subjetivos específicos requeridos por el tipo; siendo hasta la corriente finalista en 
Revista de Investigación

Año 13.

Académica sin Frontera

Núm. 33

ISSN: 2007-8870

https://revistainvestigacionacademicasinfrontera.unison.mx/index.php/RDIASF

Recibido el 17 de junio de 2020. Dictaminado mediante arbitraje favorablemente 30 de noviembre de 2020.

donde la conformación del tipo penal incluyo además, del tipo objetivo con sus elementos subjetivos específicos requeridos por el tipo, el dolo y la culpa.

Aunque todas las escuelas tuvieron grandes aportaciones, la Escuela Finalista da un giro a la visión que se tenía de los elementos configuradores del delito, ya que a pesar de continuar con la misma visión de un presupuesto y sus tres categorías, el nexo entre la conducta y el resultado se justificó de manera distinta.

Hanz Welzel (p. 47, Márquez: 2003) fue el principal exponente de esta escuela, él decía que la conducta no es relevante para el derecho penal solo por su causalidad, sino porque es dirigida por una finalidad que guía el proceso causal, lo anterior se puede apreciar de la distinción entre actos preparatorios y los de ejecución, otra de las grandes aportaciones de esta escuela fue en la categoría de tipicidad se configura por tipo subjetivo, que comprende los elementos objetivos y los normativos, y por tipo subjetivo que comprende los elementos subjetivos específicos distintos del dolo y la culpa. Por su parte, los elementos objetivos son aquellos que se perciben a través de los sentidos y que se acreditan de manera científica.

Los elementos normativos requieren de una valoración cultural o jurídica para establecer si el hecho corresponde o no a la descripción prevista en el tipo penal, finalmente los elementos subjetivos específicos son aquellos requeridos por el tipo penal que se constituyen en especiales ánimos, tendencias, intenciones o fines distintos del dolo, la principal diferencia de la conformación de la tipicidad con las otras escuelas es que dentro del tipo subjetivo incluye el dolo o la culpa, tomándolos de la culpabilidad.

\subsubsection{Orden lógico de prelación de los elementos del delito.}


Año 13.

Revista de Investigación

Núm. 33

Académica sin Frontera

https://revistainvestigacionacademicasinfrontera.unison.mx/index.php/RDIASF

Recibido el 17 de junio de 2020. Dictaminado mediante arbitraje favorablemente 30 de noviembre de 2020.

La teoría del delito deberá estudiarse bajo un orden lógico de prelación de los elementos del mismo, en su obra "Teoría Jurídica del Delito", Mario Octavio Vázquez Padilla (Vázquez: 2004), nos plasma el siguiente orden:

\section{Aspectos positivos:}

Conducta

Tipicidad

Antijuricidad

Culpabilidad

Punibilidad

\section{Aspectos Excluyentes:}

Ausencia de conducta

Atipicidad

Causas de justificación

Causas de Inculpabilidad

Excusas absolutorias

\section{Ausencia de conducta:}

Vis absoluta

Vis maior

Movimiento reflejo

Transe hipnótico

Sueño

Sonambulismo

\section{Atipicidad:}

Falta de elementos o referencias esenciales del tipo

Ausencia de imputación objetiva

Error invencible de tipo

Caso fortuito

Tratamiento quirúrgico

Consentimiento del titular 
Año 13.

Revista de Investigación

Núm. 33

Académica sin Frontera

ISSN: 2007-8870

https://revistainvestigacionacademicasinfrontera.unison.mx/index.php/RDIASF

Recibido el 17 de junio de 2020. Dictaminado mediante arbitraje favorablemente 30 de noviembre de 2020.

\section{Causas de justificación:}

Legítima defensa

Estado de necesidad justificante

Ejercicio de un derecho

Cumplimiento de un deber legal

Impedimento legitimo

Consentimiento del titular

\section{Causas de inculpabilidad:}

Inimputabilidad

Error invencible de prohibición
a) Directo
b) Indirecto
c) Obediencia jerárquica
d) Inexigibilidad de otra conducta
a) Estado de necesidad exculpante
b) Temor fundado
c) Encubrimiento entre pariente y de otras.

\section{Excusas absolutorias:}
a) Aborto culposo
b) Robo de escasa cuantía entre parientes
C) Desistimiento voluntario del delito
d) otras 
Año 13.

Revista de Investigación

Núm. 33

Académica sin Frontera

https://revistainvestigacionacademicasinfrontera.unison.mx/index.php/RDIASF

Recibido el 17 de junio de 2020. Dictaminado mediante arbitraje favorablemente 30 de noviembre de 2020.

Del esquema citado con anterioridad trataremos de estructurar la teoría del delito bajo cuatro elementos, donde cada uno de ellos componen el hecho punible en el siguiente orden: Conducta, Tipicidad, Antijuricidad y Culpabilidad.

Cada elemento presenta una serie de requisitos para su configuración.

a) La conducta requiere, voluntad y exteriorización

b) La tipicidad la configuración de los elementos objetivos y subjetivos del tipo

c) La Antijuricidad requiere la ausencia de causas de justificación

d) La culpabilidad requiere imputabilidad, exigibilidad y conocimiento de su actuar antijurídico.

\subsection{Conducta.}

El derecho penal tiene como referencia a la acción humana de tal manera que necesitamos determinar los comportamientos humanos que producen factores con relevancia jurídico penal. Es por ello que analizaremos cada uno de los elementos de la teoría del delito.

La conducta según la Real Academia Española (Real Academia Española: 1780), es el movimiento corporal voluntario que causa un resultado distinto del propio acto, ósea, acción positiva más relación de causalidad más resultado. En primer lugar debemos establecer que la conducta debe derivarse de una persona humana, es decir no de fenómenos naturales ni de las bestias, así mismo no tendrá relevancia jurídico penal las intenciones ni los ánimos internos y mucho menos aquellos actos donde esté ausente la voluntad del sujeto activo. En este sentido la conducta dolosa tiene dos fases interna y externa; la primera se configura con la 
Año 13.

Núm. 33
Revista de Investigación

Académica sin Frontera

ISSN: 2007-8870

https://revistainvestigacionacademicasinfrontera.unison.mx/index.php/RDIASF

Recibido el 17 de junio de 2020. Dictaminado mediante arbitraje favorablemente 30 de noviembre de 2020.

ideación, deliberación y resolución; la segunda por la exteriorización, la preparación, y la ejecución.

Por lo tanto analizaremos las excluyentes de la conducta. De la siguiente manera:

1) Fuerza física irresistible: Es la causación de un resultado sin voluntad. Puede provenir de la naturaleza (Vis Maior) o del hombre (Vis Absoluta). En ambos casos debe tratarse de una fuerza material - no moral - que imposibilita al sujeto para moverse o dejarse de mover, es decir aquella energía, proveniente de la naturaleza o de un tercero que anula la capacidad volitiva del sujeto.

2) Movimiento reflejo: Son movimientos no controlados o producidos para la voluntad de las personas, suelen manifestarse como respuesta a estímulos aplicados en las articulaciones del cuerpo.

3) Transe Hipnótico: Es un procedimientos de carácter científico mediante el cual una persona se encuentra en un sueño inducido de forma artificial por parte de un tercero, quien lo condiciona a llevar a cabo una conducta ajena a su voluntad.

4) Sueño: Es el estado fisiológico natural de las personas consistentes en el relajamiento muscular, disminución de funciones orgánicas y baja temperatura corporal.

5) Sonambulismo: Es el estado mediante el cual una persona, al estar dormida, puede realizar acciones ausentes de voluntad.

La ausencia de voluntad de las personas o su exteriorización elimina la conducta por lo tanto no hay razón sustantiva para sostener la presencia de un ilícito penal. 
Revista de Investigación

Año 13.

Académica sin Frontera

Núm. 33

ISSN: 2007-8870

https://revistainvestigacionacademicasinfrontera.unison.mx/index.php/RDIASF

Recibido el 17 de junio de 2020. Dictaminado mediante arbitraje favorablemente 30 de noviembre de 2020.

\subsection{Tipicidad.}

Es un término que le debemos a jurista Aleman Ernest Beling quien argumento que todo hecho, para considerarse delito y por ende de interés del derecho penal, debe superar el juicio de tipicidad es decir, un análisis de la conducta y su adecuación exacta a la descripción establecida en la legislación penal o leyes especiales. La forma idónea para saber si un hecho puede ser considerado delito, es realizando un examen de encuadre en relación con el tipo penal concreto, lo que conocemos como juicio de tipicidad

Para efecto de estudiar la tipicidad es preciso definir el concepto y elementos del tipo penal. El ilícito penal debe estar establecido previamente en una Ley.

El tipo penal es una figura creada por el legislador y se describen en la parte especial de los Códigos Penales o Leyes especiales, conformándose por elementos objetivos normativos o subjetivos. En nuestra legislación no todos los tipos penales cuentan con los tres elementos, en virtud de que el legislador en algunos casos solamente doto de uno o dos elementos.

Elementos objetivos del tipo: Son aquellos que pueden ser percibidos de forma lógica y natural mediante los sentidos, o bien de manera científica mediante un conocimiento o técnica pericial. De acuerdo con Rubén Quintino Zepeda (Quintino: 2019), dentro de los elementos objetivos se encuentran:

1) Sujeto activo

2) Sujeto pasivo

3) Calidad del sujeto activo

4) Calidad del sujeto pasivo 
Año 13.

Revista de Investigación

Núm. 33

Académica sin Frontera

https://revistainvestigacionacademicasinfrontera.unison.mx/index.php/RDIASF

Recibido el 17 de junio de 2020. Dictaminado mediante arbitraje favorablemente 30 de noviembre de 2020.

5) Conducta

6) Bien jurídico

7) Objeto material

8) Circunstancias de tiempo lugar modo y ocasión

9) Medios comisivos

10)Nexo causal

11)Resultado (formal o material)

Sujeto activo: Es la persona que provoca el hecho criminal en su calidad de autor o participe.

Sujeto Pasivo: Es el titular del bien jurídico que recibe en su prejuicio de forma dolosa o culposa una afectación directa que le genere una lesión o peligro a su bien jurídico (Victima).

Calidad de sujeto activo: Los tipos penales vienen referidos a un sujeto anónimo con las expresiones: Al que, El que, etc. Sin embargo existen excepciones a la regla en la que estos solo pueden ser realizados por sujetos que poseen determinados elementos objetivos de autoría o participación.

Calidad de sujeto pasivo: Cualquier persona puede ser sujeto pasivo del delito y de la acción, además habrá tipos penales que requieran una calidad específica del sujeto pasivo, entre los cuales podemos mencionar el feminicidio, delitos cometidos por funcionarios públicos, Corrupción de menores, etc. Para lo cual será necesario que el sujeto pasivo acredite su condición.

Conducta: como ya lo establecimos, la conducta comprende a todo aquel Movimiento corporal voluntario que realiza una persona causando un resultado 
Año 13.

Revista de Investigación

Núm. 33

Académica sin Frontera

https://revistainvestigacionacademicasinfrontera.unison.mx/index.php/RDIASF

Recibido el 17 de junio de 2020. Dictaminado mediante arbitraje favorablemente 30 de noviembre de 2020.

distinto del propio acto, ósea, acción positiva más relación de causalidad más resultado.

La conducta como manifestación de voluntad del sujeto consiste en hacer o dejar de hacer una actividad o mandamiento legal y se puede manifestar en las siguientes formas: Acción, Omisión, Comisión por omisión.

Bien Jurídico: Los bienes jurídicos pueden ser de carácter personal y supra personal. El primero es aquel protegido por la norma penal respecto de un determinado individuo con el objeto de facilitar la armonía social y los segundos son aquellos que sin pertenecer a determinados individuos resultan de interés para toda la sociedad, es decir aquellas conductas que no solo le perjudican a un individuo en exclusivo si no que competen a todos por ser miembros de la sociedad.

Objeto Material: Es la persona o cosa sobre la que recae la conducta nuclear.

Circunstancias de tiempo modo u ocasión: Son aquellas cuya acción nuclear exigen se realice en circunstancias de carácter temporal, espacial o situacional en las que por regla general, se fundamenta las agravantes 0 atenuantes de la pena y excepcionalmente la tipicidad.

Medios comisivos: La conducta nuclear del tipo puede realizarse a través de diversos medios. En ocasiones, el Legislador define los medios de comisión de una conducta, que si no se realiza a través de estos medios queda excluida de la tipicidad. Ejemplo: La violencia física o moral en la violación, el engaño o aprovechamiento del error en el fraude, la seducción o el engaño en el estupro, Etc.

Nexo Causal: Es la relación lógica natural existente entre la conducta desplegada por el sujeto activo y el resultado causado en dicha conducta.

Resultado Formal o Material: Los tipos penales en cuanto al resultado se clasifican en formales o materiales, siendo los primeros aquellos que no requieren 
Año 13.

Revista de Investigación

Núm. 33

Académica sin Frontera

https://revistainvestigacionacademicasinfrontera.unison.mx/index.php/RDIASF

Recibido el 17 de junio de 2020. Dictaminado mediante arbitraje favorablemente 30 de noviembre de 2020.

generar un cambio perceptible en la realidad y los segundos si logran cambiar la realidad.

\subsubsection{Elementos normativos del tipo penal.}

Son aquellos cuyo significado podemos encontrarlo acudiendo a normas culturales o jurídicas, por ejemplo ajeneidad, contra la moral sin derecho, etc.

Rubén Quintino Zepeda (Quintino: 2019), señala que los elementos normativos del tipo penal son aquellos que solo pueden ser entendidos dentro de un contexto de una norma de cualquier índole, sea jurídica o cultural.

\subsubsection{Elementos subjetivos del tipo penal:}

Son aquellos que están ligados a la psique, del sujeto activo al momento de cometer la conducta criminal. Para su estudio se dividen en elementos subjetivos genéricos, como el dolo y la culpa y elementos subjetivos específicos, es decir, los ánimos, fines o intenciones del sujeto al realizar la conducta.

\subsubsection{Dolo.}

La concepción finalista de la acción incluye el estudio del dolo en el área de la tipicidad, por lo tanto el dolo significa conocer, querer y aceptar la conducta descrita en la parte objetiva del tipo.

Por lo tanto el dolo está conformado por dos clases de componentes: uno de carácter cognositivo y otro de carácter volitivo.

a) Cognitivo: alude a que el sujeto conoce y entiende la conducta descrita en el tipo. 
Año 13.

Revista de Investigación

Núm. 33

Académica sin Frontera

https://revistainvestigacionacademicasinfrontera.unison.mx/index.php/RDIASF

Recibido el 17 de junio de 2020. Dictaminado mediante arbitraje favorablemente 30 de noviembre de 2020.

b) Volitivo: El sujeto activo conoce previamente la conducta que está realizando, además quiere y acepta el resultado querido u otro distinto.

\section{Tipos de dolo:}
a) Dolo directo o de primer grado
b) Dolo Indirecto o de consecuencias necesarias
c) Dolo eventual
d) Dolo Indeterminado
e) Dolo de ímpetu

\section{Dolo directo o de primer grado:}

Es la coincidencia entre la intención perseguida por el sujeto activo y el resultado obtenido, es decir el objetivo propuesto genera la realización de la conducta y el resultado querido.

\section{Dolo indirecto o de consecuencias necesarias:}

En este tipo de dolo el resultado típico no es querido de manera directa por el sujeto activo, sin embargo asume su producción en virtud de que no puede evitar el resultado aunque no lo desee.

\section{Dolo eventual:}

En este tipo de dolo el sujeto activo posee de antemano la imagen mental del resultado y a pesar de ello realiza la acción con una actitud de indolencia, lo que equivale a consentir la afectación del bien jurídico.

\section{Dolo indeterminado:}

Se presenta cuando el sujeto activo lleva a cabo una conducta cuya magnitud o resultado es imposible de cuantificar a priori. 
Año 13.

Núm. 33
Revista de Investigación

Académica sin Frontera

ISSN: 2007-8870

https://revistainvestigacionacademicasinfrontera.unison.mx/index.php/RDIASF

Recibido el 17 de junio de 2020. Dictaminado mediante arbitraje favorablemente 30 de noviembre de 2020.

\section{Dolo de ímpetu:}

Es aquel que se ejecuta en un estado de exaltación por lo tanto disminuye la imputabilidad y generalmente es motivo de atenuación de la pena.

\subsubsection{Culpa.}

Todo delito culposo, se origina a partir de una conducta dirigida a la obtención de un resultado anticipado mentalmente o sin representación del mismo, no obstante que la afectación del bien jurídico no es deseado (Vazquez: 2002).

La creación del delito culposo es de data resiente. Pese que entre los romanos existió una temprana distinción entre los actos intencionales o no intencionales, el hecho imprudente era considerado un quasil delitim más propio del ámbito privado que del penal. Al respecto, nuestra legislación asume el sistema cerrado de los delitos susceptibles de incriminación culposa tal y como se estable en el artículo 64 del Código Penal del Estado de Sonora:

Artículo 64.- Los delitos culposos se sancionarán con prisión de tres días a seis años, multa de diez a doscientas Unidades de Medida y Actualización y suspensión hasta por diez años o privación definitiva del derecho para ejercer profesión, oficio, autorización, licencia o permiso, que motivó el delito. Además de aquellos delitos que incluyan específicamente a la culpa como elemento constitutivo del tipo, y respecto de los cuales la ley señale una pena específica, las sanciones por delito culposos (sic) solamente se impondrán a los delitos previstos en los siguientes artículos: 134, 150, 151, 242, 243, 244, 249, 252, 253, 254, 258, excluyendo el homicidio calificado con premeditación, alevosía, ventaja y traición, 265, 267, 275, 299, 326, 327 y 329, fracción IV. Siempre que al delito doloso corresponda sanción 
Año 13.

Revista de Investigación

Académica sin Frontera

Núm. 33

ISSN: 2007-8870

https://revistainvestigacionacademicasinfrontera.unison.mx/index.php/RDIASF

Recibido el 17 de junio de 2020. Dictaminado mediante arbitraje favorablemente 30 de noviembre de 2020.

alternativa o trabajo en favor de la comunidad como sanción autónoma, aprovechará esta situación al sentenciado por culpa.

\section{Clasificación de la culpa.}

Podemos distinguir dos formas de culpa consiente o con representación mental del resultado, e inconsciente sin representación mental del resultado.

a) Culpa Consciente. Se presenta cuando el sujeto activo ha previsto que el resultado típico puede sobrevenir a consecuencia de su acción, pero confía en que su habilidad de estresa u otros factores, impedirán el mismo.

b) Culpa Inconsciente. En esta culpa el sujeto activo no tiene representación mental del resultado, no existe un conocimiento efectivo del peligro que la realización del acto supone para el bien jurídico, sino que ese conocimiento es potencial, es decir mediante la aplicación del cuidado requerido a la situación concreta, hubiera podido proveer la producción del resultado

\subsubsection{Elementos subjetivos del tipo, diferentes al dolo.}

Son aquellos componentes de la descripción típica, que presuponen una determinada actitud intelectual o anímica del sujeto activo y para su debida conformación requiere que se acredite un determinado fin, ánimo o intención para así poder afirmar que nos encontramos ante una conducta típica.

\subsubsection{Aspectos negativos de la tipicidad.}

El tipo penal es la descripción de un hecho descrito en la legislación penal o en una ley especial en tanto la tipicidad será la adecuación exacta y plena de la conducta al tipo. Al respecto Rubén Quintino Zepeda (Quintino: 2019), señala que si 
Año 13.

Revista de Investigación

Núm. 33

Académica sin Frontera

https://revistainvestigacionacademicasinfrontera.unison.mx/index.php/RDIASF

Recibido el 17 de junio de 2020. Dictaminado mediante arbitraje favorablemente 30 de noviembre de 2020.

la conducta del sujeto activo en su presupuestos esenciales, se relacionan con el tipo penal entonces el comportamiento será típico. Por lo tanto el elemento negativo lo constituye las causas de atipicidad que de actualizarse una de ellas la conducta no se ajustaría al tipo por lo tanto seria licita; las causas de atipicidad las encontramos en el artículo 405 del Código Penal de Procedimientos Penales inciso I y en el artículo 13 apartado A inciso I del Código Penal del Estado de Sonora.

Se consideran causas de Atipicidad las siguientes:

a) Ausencia de voluntad o de conducta

b) Falta de alguno de los elementos del tipo penal

c) El consentimiento de la víctima que recaiga sobre algún bien jurídico disponible.

d) El error de tipo vencible que recaiga sobre algún elemento del tipo penal que no admita, de acuerdo con el catálogo de delitos susceptibles de configurarse de forma culposa previstos en la legislación penal aplicable.

e) Error de tipo invencible.

La ausencia de tipicidad en la conducta impide avanzar con los juicios de valor o análisis sobre la Antijuricidad y la culpabilidad, en virtud de que, no existen las condiciones para afirmar que el hecho es una conducta delictiva y por ende no genera consecuencia jurídico - penal contra el autor de alguna conducta atípica.

\subsection{Antijuricidad.}

Según Mario Octavio Vázquez Padilla (Vázquez: 2004), este elemento del delito, es un juicio desaprobatorio que recae sobre una acción típica, por no estar justificada en alguna parte del ordenamiento jurídico en general. La Antijuricidad 
Año 13.

Académica sin Frontera

Núm. 33

ISSN: 2007-8870

https://revistainvestigacionacademicasinfrontera.unison.mx/index.php/RDIASF

Recibido el 17 de junio de 2020. Dictaminado mediante arbitraje favorablemente 30 de noviembre de 2020.

consta de dos elementos; uno positivo que implica la tipicidad y otro negativo que supone la no concurrencia de alguna causa de justificación.

Por su parte Barja de Quiroga López (Barja: 2002 ), dice que la Antijuricidad es el acto voluntario típico que contraviene el presupuesto de la norma penal, lesionando o poniendo en peligro bienes o intereses tutelados por el derecho. Es un juicio impersonal objetivo sobre la contradicción existente entre el hecho y el ordenamiento jurídico.

El finalista Hans Welzel (p. 47, Márquez: 2003) definió a la Antijuricidad como la contradicción de la conducta típica con la totalidad del ordenamiento jurídico.

La Antijuricidad se integra por dos vertientes: en sentido formal y en sentido material.

La Antijuricidad formal se presenta cuando una conducta violenta lo dispuesto en la norma penal, mientras que la Antijuricidad material vulnera la norma al poner en peligro el bien jurídico tutelado o protegido por la misma.

La Antijuricidad reconoce causas que justifican la conducta típica del sujeto activo misma que excluyen el delito, pero no el injusto penal, es decir una conducta típica pero justificada por la ley no es punible.

Las causas de justificación las podemos encontrar en el artículo 13 apartado b, del Código Penal del Estado de Sonora.

B.- Causas de justificación: I. Consentimiento presunto. Se presume que hay consentimiento, cuando el hecho se realiza en circunstancias tales que permitan suponer fundadamente que, de haberse consultado al titular del bien o a quien esté legitimado para consentir, éstos hubiesen otorgado el consentimiento; II. Legítima defensa: Se repela una agresión real, actual o inminente y sin derecho, en defensa de bienes jurídicos propios o ajenos, siempre que exista necesidad de la defensa 
Año 13.

Académica sin Frontera

Núm. 33

ISSN: 2007-8870

https://revistainvestigacionacademicasinfrontera.unison.mx/index.php/RDIASF

Recibido el 17 de junio de 2020. Dictaminado mediante arbitraje favorablemente 30 de noviembre de 2020.

empleada y no medie provocación dolosa suficiente e inmediata por parte del agredido o de su defensor. Se presumirá que concurren los requisitos de la legítima defensa, respecto de aquél que cause un daño, a quien a través de la violencia, ¿ escalamiento o por cualquier otro medio trate de penetrar sin derecho, a su hogar o sus dependencias, a los de su familia o los de cualquier persona que tenga el mismo deber de defender 0 al sitio donde se encuentren bienes jurídicos propios o ajenos de los que tenga la misma obligación; o bien, cuando lo encuentre en alguno de esos lugares, en circunstancias tales que revelen la posibilidad de una agresión; III. Estado de necesidad justificante: Se obre por la necesidad de salvaguardar un bien jurídico propio o ajeno, de un peligro real, actual o inminente, no ocasionado dolosamente por el sujeto, lesionando otro bien de menor valor que el salvaguardado, siempre que el peligro no sea evitable por otros medios y el sujeto activo no tuviere el deber jurídico de afrontarlo; IV. Cumplimiento de un deber o ejercicio de un derecho: La acción o la omisión se realicen en cumplimiento de un deber jurídico o en ejercicio de un derecho, siempre que exista necesidad racional de la conducta empleada para cumplirlo o ejercerlo.

Además el Código Nacional de Procedimientos Penales en el artículo 405 fracción II igualmente nos dice cuáles son las causas de justificación.

405: II. Son causas de justificación: el consentimiento presunto, la legítima defensa, el estado de necesidad justificante, el ejercicio de un derecho y el cumplimiento de un deber.

\subsection{Culpabilidad.}

La culpabilidad es el último juicio de valor para establecer si un hecho es delito o no lo es, precisando las condiciones que determinan si el autor de una acción típica y anti jurídica sea legalmente responsable de la misma. 
Año 13.

Revista de Investigación

Académica sin Frontera

Núm. 33

ISSN: 2007-8870

https://revistainvestigacionacademicasinfrontera.unison.mx/index.php/RDIASF

Recibido el 17 de junio de 2020. Dictaminado mediante arbitraje favorablemente 30 de noviembre de 2020.

La culpabilidad corresponde al grado de reprochabilidad del imputado respecto del hecho considerado delito, debiendo demostrar que el sujeto es imputable y que conocía la Antijuricidad de su conducta, no debiendo obrar en su favor causas de inculpabilidad.

\subsubsection{La imputabilidad como presupuesto de la culpabilidad}

La imputabilidad se obtiene en base a dos aspectos: biológico o maduracional 0 psiquiátrico o sanidad mental.

Aspecto Maduracional: para analizar este tema habremos de recurrir a la convención internacional de los derechos del niño, misma que reconoce que una persona deja de ser niño al cumplir los 18 años de edad y por lo tanto se le considera imputable. Al respecto el Código Penal del Estado de Sonora en el Artículo 116 establece: que la responsabilidad penal solo es exigible a las personas que hayan cumplido 18 años antes de cometer el acto u omisión punible que se le imputa.

Respecto de la capacidad del sujeto activo para comprender el hecho o la conducta antijurídica que realizo y para poderlo considerar imputable es necesario que no padezca, al momento de realizar el injusto, algún tipo de enajenación o trastorno mental que le impida cumplir con la norma penal.

\subsubsection{Imputabilidad disminuida.}

Consiste en la posibilidad de que el sujeto activo presente algún rasgo de incapacidad mental, pero no lo incapacita para conocer y entender el alcance de su conducta es decir no es inimputable totalmente por lo que se le aplicara una pena atenuada o disminuida en razón a sus facultades. 
Año 13.

Revista de Investigación

Núm. 33

Académica sin Frontera

https://revistainvestigacionacademicasinfrontera.unison.mx/index.php/RDIASF

Recibido el 17 de junio de 2020. Dictaminado mediante arbitraje favorablemente 30 de noviembre de 2020.

\section{Acciones libres de causa.}

Es un auto provocación del sujeto activo para posteriormente llevar a cabo un delito, misma que no se considera causa de inimputabilidad en virtud de que el mismo se ubicó voluntariamente en ese estado de conciencia.

\section{Conciencia de Antijuricidad.}

Es la etapa de estudio de la culpabilidad en la cual se analiza si el sujeto activo al momento de realizar la conducta tenía conocimiento de la prohibición de la misma.

\section{No exigibilidad de otra conducta.}

Para que el juzgador pueda afirmar que una conducta es exigible al sujeto es necesario que se ubique en el mismo contexto y circunstancias que enfrento el imputado al momento de llevar a cabo la conducta que se le atribuye y así poder determinar si a éste le resulta exigible no haberse comportado de forma distinta.

\section{Causas de inculpabilidad previstas en el artículo 13 inciso C, del Código Penal del Estado de Sonora.}

13 C.- Causas de inculpabilidad: I.- Error de prohibición invencible: Se realice la acción o la omisión bajo un error invencible, respecto de la ilicitud de la conducta, ya sea porque el sujeto desconozca la existencia de la ley o el alcance de la misma o porque crea que está justificada su conducta; II.- Estado de necesidad disculpante: Se obre por la necesidad de salvaguardar un bien jurídico propio o ajeno, de un peligro real, actual o inminente, no ocasionado dolosamente por el sujeto, lesionando otro bien de igual valor que el salvaguardado, 5 siempre que el peligro no sea evitable por otros medios y el sujeto activo no tuviere el deber jurídico de afrontarlo; 
Revista de Investigación

Año 13.

Académica sin Frontera

Núm. 33

ISSN: 2007-8870

https://revistainvestigacionacademicasinfrontera.unison.mx/index.php/RDIASF

Recibido el 17 de junio de 2020. Dictaminado mediante arbitraje favorablemente 30 de noviembre de 2020.

III.- Inimputabilidad y acción libre en su causa: Al momento de realizar el hecho típico, el agente no tenga la capacidad de comprender el carácter ilícito de aquél o de conducirse de acuerdo con esa comprensión, en virtud de padecer trastorno mental o desarrollo intelectual retardado, a no ser que el sujeto hubiese provocado su trastorno mental para en ese estado cometer el hecho, en cuyo caso responderá por el resultado típico producido en tal situación.

Las acciones libres en su causa culposamente cometidas se resolverán conforme a las reglas generales de los delitos culposos. IV.- Inexigibilidad de otra conducta: En atención a las circunstancias que concurren en la realización de una conducta ilícita, no sea racionalmente exigible al sujeto una conducta diversa a la que realizó, en virtud de no haberse podido conducir conforme a derecho. Las causas que excluyen el delito se resolverán de oficio, en cualquier estado del proceso.

De igual manera en el Código Nacional de Procedimientos Penales en su artículo 405 fracción III nos ilustra sobre las causas de inculpabilidad.

Son causas de inculpabilidad: el error de prohibición invencible, el estado de necesidad disculpante, la inimputabilidad, y la inexigibilidad de otra conducta. De ser el caso, el Tribunal de enjuiciamiento también podrá tomar como referencia que el error de prohibición vencible solamente atenúa la culpabilidad y con ello atenúa también la pena, dejando subsistente la presencia del dolo, igual como ocurre en los casos de exceso de legítima defensa e imputabilidad disminuida.

\section{Forma de intervención.}

La doctrina reconoce diversas formas de intervención y participación del sujeto activo en el hecho criminal. Nuestro Código Penal del Estado de Sonora, en el artículo 11 puntualmente establece: 
Revista de Investigación

Año 13.

Académica sin Frontera

Núm. 33

ISSN: 2007-8870

https://revistainvestigacionacademicasinfrontera.unison.mx/index.php/RDIASF

Recibido el 17 de junio de 2020. Dictaminado mediante arbitraje favorablemente 30 de noviembre de 2020.

ARTÍCULO 11.- Formas de intervención. Las personas pueden intervenir en la realización de un delito, conforme a las siguientes disposiciones: I. Es autor directo: quien lo realice por sí; II. Es coautor: quien lo realice conjuntamente con otro u otros autores; III. Es autor mediato: quien lo lleve a cabo sirviéndose de otro como instrumento; IV. Es partícipe inductor: quien determine dolosamente al autor a cometerlo; V. Es partícipe cómplice: quien dolosamente preste ayuda o auxilio al autor para su comisión; y VI. Es partícipe encubridor: quien con posterioridad a su ejecución, auxilie al autor por acuerdo anterior al delito. Quienes únicamente intervengan en la planeación o preparación del delito, así como quienes determinen a otro o le presten ayuda o auxilio, sólo responderán si el hecho antijurídico del autor alcanza al menos el grado de tentativa del delito que se quiso cometer. La instigación y la complicidad sólo son admisibles en los delitos dolosos. En la aplicación de las reglas establecidas en este Código, y para los efectos de la responsabilidad penal, toda persona se presumirá inocente.

\section{Concurso de delitos.}

El concurso se presenta cuando la ejecución de una o más conductas producen varios hechos considerados delito sin que exista la posibilidad de que uno excluya al otro. Por lo tanto el concurso de delitos será ideal o real, tal como lo establece el artículo 15 y 70 del Código Penal del Estado de Sonora.

ARTíCULO 15.- Existe concurso ideal, cuando con una sola acción o una sola omisión se cometen varios delitos. Existe concurso real, cuando con pluralidad de acciones $\mathrm{u}$ omisiones se cometen varios delitos. No hay concurso cuando las conductas constituyen un delito continuado o permanente.

ARTICULO 70.- En los casos de concurso real, se impondrá la sanción establecida al delito que merezca pena mayor, la que se aumentará con la suma de 
Revista de Investigación

Año 13.

Académica sin Frontera

Núm. 33

ISSN: 2007-8870

https://revistainvestigacionacademicasinfrontera.unison.mx/index.php/RDIASF

Recibido el 17 de junio de 2020. Dictaminado mediante arbitraje favorablemente 30 de noviembre de 2020.

las correspondientes a los demás delitos, individualizadas 18 cada una de ellas, según los términos mínimos y máximos establecidos en la ley, sin que pueda exceder de cincuenta años, cuando se trate de la pena de prisión. En el supuesto de concurso ideal, se aplicará la sanción que corresponda al delito que merezca pena mayor, la cual podrá aumentarse hasta en una mitad más del máximo de su duración, a juicio del juez. Lo previsto en este párrafo no comprende los casos en que la ley dispone que, por circunstancias modificativas o calificativas, una sanción determinada deba agravarse con otra, o ésta deba imponerse sin perjuicio de aquélla. Tratándose de concurso ideal, si el delito fue dolosamente ejecutado para violar varias disposiciones penales o varias veces la misma disposición, o se realizó a sabiendas de que tal posibilidad ocurriera, se sancionará conforme a las reglas del concurso real.

\section{Teoría del caso}

\subsection{Teoría del caso.}

La reforma constitucional del 18 de junio del 2008 en materia de justicia y seguridad en México es el parte aguas para una nueva forma metodológica en la investigación de los hechos probablemente constitutivos de delito. Surge la teoría del caso como una herramienta indispensable para el correcto y adecuado manejo del caso concreto que se investiga desde que se tiene la noticia criminal hasta, hasta que la sentencia causa ejecutoria. 
Año 13.

Académica sin Frontera

Núm. 33

ISSN: 2007-8870

https://revistainvestigacionacademicasinfrontera.unison.mx/index.php/RDIASF

Recibido el 17 de junio de 2020. Dictaminado mediante arbitraje favorablemente 30 de noviembre de 2020.

La teoría del caso es el faro que brinda luz y orienta a las partes intervinientes en el proceso penal acusatorio en relación a la dirección que deben tomar para responder a las preguntas mágicas del hecho criminal: ¿qué sucedió?, ¿el hecho tiene relevancia jurídico-penal?, ¿Cuáles elementos integran el tipo penal de que se trata?, ¿Quién o quienes lo cometieron?, Cómo se puede probar la probable responsabilidad de o los imputados?, ¿Quién o quiénes son las víctimas?, ¿Cuál es el monto de la reparación del daño?, ¿es aplicable una causa excluyente de responsabilidad penal al hecho criminal?, etcétera.

La Teoría del Caso constituye una herramienta metodológica fundamental de apoyo y respaldo en la estrategia de litigación para la parte acusadora y la defensa en el proceso penal acusatorio, es decir no se limita simplemente a la narración de hechos fácticos, además debe existir un planteamiento claro sobre la acusación del Ministerio Público y la defensa, en torno a los hechos penalmente relevantes, el material probatorio que le dan soporte y los fundamentos jurídicos que lo validan.

Es decir la teoría del caso no solo se utiliza durante la audiencia del juicio oral, como sostienen algunos operadores del sistema. Es importante mencionar que la teoría del caso no solamente incumbe a las partes intervinientes, sino también al juzgador, en virtud de que las partes a través de este medio le brindan la información fáctica, probatoria y jurídica que le permitirá contar con los elementos necesario para en su momento procesal oportuno resolver lo que a derecho corresponda.

La Teoría del Caso: "es el planteamiento metodológico que cada una de las partes debe realizar desde el primer momento en que han tomado conocimiento de los hechos, con la finalidad de dotar de un solo sentido, significado u orientación a los hechos, normas jurídicas-sustantivas y procesales-, así como el material probatorio, también conocido como evidencias". 
Revista de Investigación

Año 13.

Académica sin Frontera

Núm. 33

ISSN: 2007-8870

https://revistainvestigacionacademicasinfrontera.unison.mx/index.php/RDIASF

Recibido el 17 de junio de 2020. Dictaminado mediante arbitraje favorablemente 30 de noviembre de 2020.

En síntesis la teoría del caso aporta a las partes intervinientes los medios o herramienta necesaria para ordenar y clasificar la información obtenida mediante indicios, entrevistas, datos de prueba, etc. $Y$ así estar en condiciones de llevar a cabo un planteamiento fáctico y probatorio de forma estratégica, basado en la información recabada, además de ordenar y clasificar dicha información, adecuándola al tipo penal concreto y poder decidir lo que más convenga a su representado en cualquier etapa del proceso, además de ejercer su capacidad argumentativa con razón y conocimiento en la audiencia de juicio oral de ser necesario llegar a tal instancia.

La teoría del caso planteada adecuadamente en sus tres teorías permite a la defensa o al Ministerio Público saber que probabilidades de obtener una sentencia absolutoria o condenatoria para su representado y así decidir la conveniencia de ir o no ir a juicio oral. En el caso concreto la defensa puede preferir una solución alterna o forma de terminación anticipada del proceso que mayormente favorezca al imputado o en la que resulte lo menos perjudicial a sus intereses procesales: El acuerdo reparatorio, la suspensión condicional de proceso a prueba o el proceso abreviado, o en su caso el Ministerio Público, dependiendo de la fortaleza de su teoría del caso podrá recurrir, además de las ya establecidas a las siguiente formas de terminación de investigación: Facultad de obtenerse de investigar, archivo temporal, no ejercicio de la acción penal o criterios de oportunidad. He ahí la importancia de contar con una Teoría del Caso metodológicamente sólida, bien sustentada en su aspecto fáctico, probatorio y legal que nos permita dignificar el rol del litigante en los tribunales y no convertir la audiencia de juicio oral en un espacio de debate falto de aplicación de derecho sustantivo y adjetivo limitada a la probanza de hechos, dejando de lado la teoría del delito o la teoría legal del caso. 
Año 13.

Revista de Investigación

Núm. 33

Académica sin Frontera

https://revistainvestigacionacademicasinfrontera.unison.mx/index.php/RDIASF

Recibido el 17 de junio de 2020. Dictaminado mediante arbitraje favorablemente 30 de noviembre de 2020.

En síntesis, la teoría del caso según Ramírez Saavedra Beatriz Eugenia (Ramírez: 2010) en su obra "Veintidós aspectos básicos de la investigación del delito", es:

1. La verdad que sostiene cada parte de acuerdo con su conocimiento e interpretación de lo sucedido.

2. Es el relato de lo sucedido de acuerdo con el punto de vista de cada una de las partes en pugna.

3. Es la articulación coherente y ordenada de las proposiciones fácticas que sustentan la posición jurídica del litigante.

4. Es la guía que debe orientar la actividad de los litigantes durante el proceso.

5. El instrumento que respalda la estrategia de la defensa o ataque que adoptara durante el litigio.

6. El punto de vista para ubicar las huellas o rastros de lo ocurrido y asignarle significado.

La Teoría del Caso, se compone de tres teorías:

1) Fáctica o de los hechos;

2) Probatoria

3) Jurídica o legal,

En consecuencia trataremos de hacer un análisis de estas tres teorías aplicables al tema que nos ocupa.

\subsubsection{La teoría fáctica de los hechos.}

Está conformada por los hechos que tengan conocimiento las partes a través de la noticia Criminal, y se consolida con indicios, entrevistas y datos de prueba 
Revista de Investigación

Año 13.

Académica sin Frontera

Núm. 33

ISSN: 2007-8870

https://revistainvestigacionacademicasinfrontera.unison.mx/index.php/RDIASF

Recibido el 17 de junio de 2020. Dictaminado mediante arbitraje favorablemente 30 de noviembre de 2020.

producto de la investigación. Este nivel de análisis llevará a las partes intervinientes el proceso acusatorio a entender y comprender como se desarrollaron realmente los hechos, a partir de su propia investigación, Sin duda la Teoría del Caso es una estratégica, dinámica, perfectible y en constante construcción que nos permite la elaboración de proposiciones de hechos que nos permitan, conocer, a ciencia cierta, la materia del hecho o hechos que se imputan, así como, identificar los hechos relevante que permitan establecer la responsabilidad o excluyente de responsabilidad del imputado".

Es importante que cada proposición fáctica esté relacionada con un elemento legal de la teoría jurídica a establecer. Las partes deberán contar con una proposición fáctica para cada elemento del delito que se pretenda acreditar 0 desacreditar en el proceso. Desde esta perspectiva, el Ministerio Público y el defensor tendrán que analizar los hechos concatenándolos con la teoría jurídica y a la teoría probatoria, a fin de establecer cuál será su estrategia general acusatoria o de defensa.

\subsubsection{La teoría jurídica o legal.}

Se utiliza para ubicar el tipo penal, la forma de intervención delictiva, excluyentes, agravantes o atenuantes de la responsabilidad penal, etcétera, ante los cuales se encuentra la partes intervinientes. De tal forma la teoría jurídica es aquella que permite al operador de la materia penal, descubrir el significado legal de un hecho típico, así las cosas, la teoría jurídica se ocupa de la determinación del tipo penal, además del marco normativo que se debe aplicar al hecho criminal comprende también la determinación del marco normativo nacional e internacional. Esta teoría, 
Año 13.

Revista de Investigación

Núm. 33

Académica sin Frontera

https://revistainvestigacionacademicasinfrontera.unison.mx/index.php/RDIASF

Recibido el 17 de junio de 2020. Dictaminado mediante arbitraje favorablemente 30 de noviembre de 2020.

al unirse a la teoría fáctica permite diferenciar un simple hecho con un hecho con relevancia jurídico-penal o considerado delito.

\subsubsection{La teoría probatoria.}

Elaboradas las teorías fácticas y jurídicas, habrá que revisar, analizar y organizar las evidencias, indicios o datos de prueba con que se cuente, con la intención de corroborar o fortalecer el dicho de las partes y poder precisar la veracidad y certeza de los hechos, y que estos tienen relevancia jurídico penal. Es decir seleccionar las los datos de prueba que en su momento procesal oportuno pueda utilizar como medio de prueba y prueba y así demostrar y acreditar la existencia de aquellas proposiciones fácticas que configuran o excluyen los elementos de la Teoría del Delito seleccionada.

Este material probatorio debe someterse a un riguroso examen para establecer si la misma no es: ilegal, ilícita, prohibida, inconducente, impertinente o hechos notorios, con el objeto de valorar su alcance probatorio, y poder de determinar si respaldan las hipótesis fácticas y jurídica que se han formulado, para posteriormente ofrecerlas y desahogarlas en la audiencia de juicio oral. Es conveniente que por cada proposición fáctica, ofrecer dos o más pruebas que nos permitan demostrar nuestro hecho y derecho, y así evitar riesgos procesales.

\section{La teoría del delito aplicada a la teoría del caso}

\section{A modo de conclusión}


Revista de Investigación

Año 13.

Académica sin Frontera

Núm. 33

ISSN: 2007-8870

https://revistainvestigacionacademicasinfrontera.unison.mx/index.php/RDIASF

Recibido el 17 de junio de 2020. Dictaminado mediante arbitraje favorablemente 30 de noviembre de 2020.

En México es común que la gran mayoría de los operadores del sistema acusatorio cree que el éxito de su teoría del caso, depende de una buena presentación y un eficiente examen probatorio en la audiencia de juicio oral mediante una serie de técnicas de oratoria e histriónicas; asimismo mediante un interrogatorio y contrainterrogatorio de testigos y peritos, convirtiendo las más de la veces las audiencias de juicio oral en un espectáculo mediático en virtud de que la materia de juicio se empobrece a meros temas de negar la veracidad de los hechos de la teoría fáctica por desconocimiento de la teoría del delito.

La teoría del caso exige un absoluto conocimiento de la teoría del delito por parte de los operadores del sistema acusatorio, porque la defensa para poder diseñar una estrategia de defensa técnica y adecuada como lo exige nuestro marco normativo, debe saber interpretar dogmáticamente la versión del imputado. Igual el Ministerio público, si pretende refutar los argumentos de la defensa necesita conocer a fondo sobre teoría del delito.

Como ya se analizó líneas anteriores el éxito de la teoría del caso no depende exclusivamente de su presentación, sino como este se construya desde la noticia criminal, se perfecciones en la investigación complementaria y se desahogue en la audiencia de juicio oral.

Para no caer en tan grave escenario consideramos en primer lugar que la teoría del caso deberá construirse de la siguiente manera:

a) La teoría fáctica o de los hechos; 
Año 13.

Revista de Investigación

Académica sin Frontera

Núm. 33

ISSN: 2007-8870

https://revistainvestigacionacademicasinfrontera.unison.mx/index.php/RDIASF

Recibido el 17 de junio de 2020. Dictaminado mediante arbitraje favorablemente 30 de noviembre de 2020.

b) La teoría jurídica o legal. Donde adecuemos los hechos probablemente constitutivos de delito en cada uno de los elementos positivos y negativos del delito 0 caso concreto. y

c) La teoría probatoria que le permita determinar con cuales elementos de prueba con que cuenta para fortalecer su teoría del caso o debilitar la teoría de la contraparte.

En segundo lugar seleccionar la teoría del delito que aplicaremos ya que si bien es cierto la teoría fáctica necesita de la teoría probatoria para verificar el hecho criminal, no menos cierto es que ambas teorías deben contar con una referencia normativa para acreditar el delito, excluyentes, agravantes, etc.

Ejemplo: Juan, Pedro, Jesús y Manuel se reúnen para ver un juego de futbol y al concluir el partido Juan se molesta porque perdió su equipo favorito e inicia una pelea con una navaja en mano tratando de causar lesiones a Pedro, pero Pedro reacciona y forcejea con Juan, introduciéndole la navaja a pedro a la altura del corazón en el forcejeo ante la presencia de Jesús y Manuel.

El Ministerio Público y la defensa tienen a los testigos quienes observaron los hechos y en la audiencia de juicio oral ambas partes deberán acreditar ante el juez de oralidad su teoría del caso, la parte acusadora la comisión del delito de homicidio y la defensa la excluyente de responsabilidad penal consistente en legítima defensa. Es de esta forma como la teoría del delito se aplica a la teoría del caso ya que permite a las partes conocer cuando una conducta es delito. 
Año 13.

Académica sin Frontera

Núm. 33

ISSN: 2007-8870

https://revistainvestigacionacademicasinfrontera.unison.mx/index.php/RDIASF

Recibido el 17 de junio de 2020. Dictaminado mediante arbitraje favorablemente 30 de noviembre de 2020.

Por lo tanto el elemento fáctico que se deberá probar como delito, deberá tener relevancia jurídico-penal, en función de alguna norma que nos ofrece la teoría del delito. Por lo tanto la importancia normativa derivada de la teoría del delito puede originarnos los elementos positivos y negativos del delito: tipicidad, antijuridicidad y culpabilidad, ausencia de conducta, atipicidad, causas de justificación, causas de inculpabilidad, formas de intervención, así como sus agravantes y atenuantes.

Como profesional del derecho debemos conocer los conceptos normativos en torno a la teoría del delito y estudiándolos desde un aspecto didáctico descubrir su relación con la teoría fáctica que las partes elaboraron, partiendo del dicho de la víctima o acusado.

Analizando lo anterior podemos decir que la teoría del delito se aplica a la teoría del caso en el momento que nos permite a los operadores del Derecho Penal conocer e identificar la relación de las normas jurídico-penales con los hechos y así darle una relevancia jurídica.

Visto lo anterior podemos concluir que la teoría del caso y la teoría del delito encuentran su conexión o aplicación práctica en la teoría jurídica o legal del primero ya que es esta el instrumento útil para atreves de la teoría del delito identificar: El tipo penal que se atribuye, grado de ejecución, forma de intervención, naturaleza de la conducta, razón de mérito atenuante, razón de mérito exculpante, razón de mérito justificante. Ante los cuales se enfrentarán los operadores del sistema acusatorio, así como las formas adjetivas de atender el hecho criminal. 
Año 13.

Revista de Investigación

Núm. 33

Académica sin Frontera

https://revistainvestigacionacademicasinfrontera.unison.mx/index.php/RDIASF

Recibido el 17 de junio de 2020. Dictaminado mediante arbitraje favorablemente 30 de noviembre de 2020.

Por lo tanto, la teoría jurídica o legal permite al ministerio público, asesor jurídico o defensor, encontrar el significado jurídico de un hecho delictuoso y al unir la teoría fáctica con la teoría jurídica nos podremos distinguir entre una simple conducta y un hecho que se puede estimar como delito.

\section{Referencias}

Amuchategui, I. (2012). Derecho Penal. Oxford. Reino Unido.

Barja, J. (2002). Derecho Penal IV: Parte general: las consecuencias jurídicas del delito, el derecho penal de ejecución. Marcial Pons, ediciones jurídicas y sociales. España.

Cuello, E. (1937). Derecho Penal I. Bosch. Barcelona.

H. Congreso de la Unión (2020). Código Nacional de Procedimientos Penales. Recuperado de:

H. Congreso de la Unión (2020). Constitución Política de los Estados Unidos Mexicanos. Recuperado de:

H. Congreso del Estado de Sonora (2019). Código Penal del Estado de Sonora. Recuperado de:

http://www.congresoson.gob.mx:81/Content/Doc leyes/doc 443.pdf http://www.diputados.gob.mx/LeyesBiblio/pdf/1 150917.pdf

http://www.diputados.gob.mx/LeyesBiblio/ref/cnpp.htm

Márquez, R. (2003). Teoría de la antijuridicidad. UNAM. México. 
Año 13.

Revista de Investigación

Núm. 33

Académica sin Frontera

https://revistainvestigacionacademicasinfrontera.unison.mx/index.php/RDIASF

Recibido el 17 de junio de 2020. Dictaminado mediante arbitraje favorablemente 30 de noviembre de 2020.

Quintino, R. (2019). Teoría del delito en el Código Nacional de Procedimientos Penales (2 ${ }^{\mathrm{a}}$. Ed.) INACIPE. México.

Ramírez, B. (2010). 22 aspectos básicos de la investigación del delito. Ubijus. México

Real Academia Española (1780). Diccionario de la Real Academia Española. Asociación de Academias de la Real Lengua Española. España

Rodríguez, L. (2020). Criminología (32ª ed.). Porrúa. México.

Valadez, M. (2017). Actos de investigación. Flores Editor y Distribuidor. México.

Valera, R. (2009). Santa Biblia, Antiguo y Nuevo Testamento. La Iglesia de Jesucristo de los Santos de los Últimos Días Salt Lake City. Utah, E.U.A.

Vázquez, B. (2010). Veintidós aspectos básicos de la investigación del delito. IBIJUS. México.

Vázquez, P. (2004) Teoría jurídica del delito. Instituto Nacional de Ciencias Penales. México. 
Año 13.

Revista de Investigación

Núm. 33

Académica sin Frontera

https://revistainvestigacionacademicasinfrontera.unison.mx/index.php/RDIASF

Recibido el 17 de junio de 2020. Dictaminado mediante arbitraje favorablemente 30 de noviembre de 2020.

\section{Directorio Institucional}

Dr. Enrique Fernando Velázquez Contreras

Rector

Dr. Ramón Enrique Robles Zepeda

Secretario General Académico

Dra. Rosa María Montesinos Cisneros

Secretaria General Administrativa

Dr. Rodolfo Basurto Álvarez

Director de Vinculación y Difusión

Dra. Adriana Leticia Navarro Verdugo

Vicerrectora de la Unidad Regional Sur

Dr. Ernesto Clark Valenzuela

Director de la División de Ciencias Económicas y Sociales

Dr. Francisco Espinoza Morales

Secretario de la División de Ciencias Económico y Sociales

Dra. Leticia María González Velásquez

Jefe del Departamento de Ciencias Económico Administrativas

Dra. Lidia Amalia Zallas Esquer

Jefe de Departamento de Ciencias Sociales 
Año 13.

Revista de Investigación

Núm. 33

Académica sin Frontera

ISSN: 2007-8870

https://revistainvestigacionacademicasinfrontera.unison.mx/index.php/RDIASF

Recibido el 17 de junio de 2020. Dictaminado mediante arbitraje favorablemente 30 de noviembre de 2020.

\section{Comité Directivo}

\section{Editor Responsable}

Dr. Francisco Espinoza Morales

Universidad de Sonora

Directora

Dra. Leticia María González Velásquez

Universidad de Sonora

Subdirector

Dr. Javier Carreón Guillen

Universidad Nacional Autónoma de México

Editor Científico

Dr. Cruz García Lirios

Universidad Autónoma del estado de México

Master Gráfico

M.T.I. Francisco Alan Espinoza Zallas

Universidad Estatal de Sonora

Nos complace anunciar que su diario, "Academic Research Journal Withoutborders" (ISSN/EISSN 2007-8870) fue evaluado positivamente en la indexación Citefactor, ahora la página de la revista está disponible en línea, en caso de cualquier problema.

Journals Master | International Innovative Journal Impact Factor (IIJIF)

Red Latinoamericana de revistas Académicas en Ciencias Sociales y Humanidades
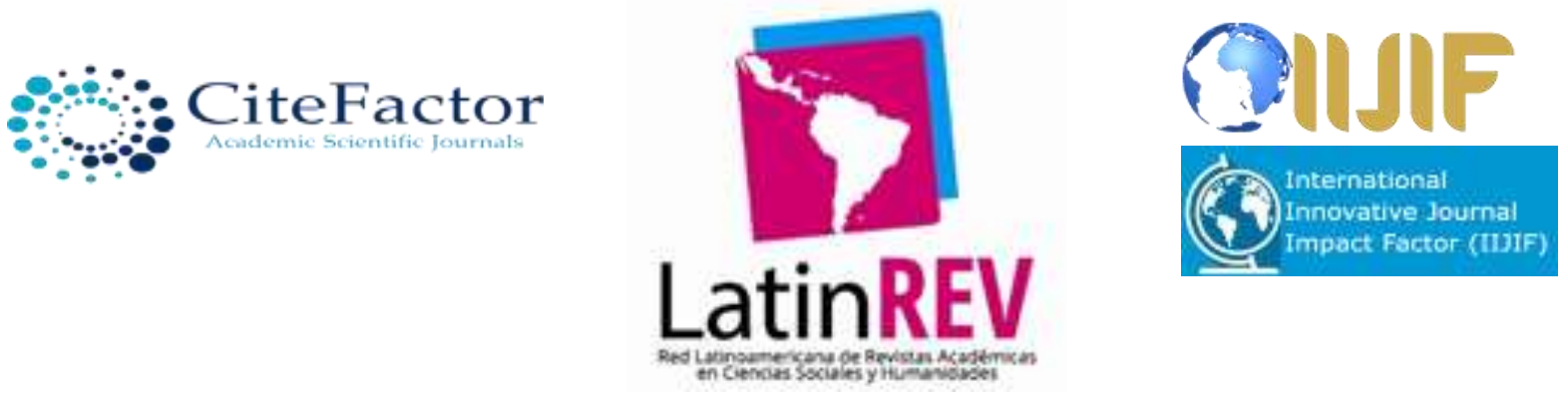
Año 13.

Revista de Investigación

Núm. 33

Académica sin Frontera

https://revistainvestigacionacademicasinfrontera.unison.mx/index.php/RDIASF

Recibido el 17 de junio de 2020. Dictaminado mediante arbitraje favorablemente 30 de noviembre de 2020.

\section{Comité editorial}

Dra. Angélica María Rascón Larios

Universidad de Sonora. México

Dra. María del Rosario Molina González

Universidad de Sonora

Dra. Francisca Elena Rochin Wong

Universidad de Sonora. México

Dra. Lidia Amalia Zallas Esquer

Universidad de Sonora. México

Dra. Beatriz Llamas Arechiga

Universidad de Sonora. México

Dr. Rogelio Barba Álvarez

Universidad de Guadalajara. México

Dra. Rosa María Rincón Ornelas

Universidad de Sonora. México

Dr. Juan Flores Preciado

Universidad de Colima. México

Dr. Amado Olivares Leal. Universidad de Sonora

Universidad de Sonora. México

Dr. Guillermo Velázquez Valadez.

Instituto Politécnico Nacional (IPN) México

Dr. Hugo Nefstalí Padilla Torres.

Universidad Estatal de Sonora. México

Dr. Luis Ramón Moreno Moreno.

Universidad Autónoma de Baja California. México

Dr. Miguel Ángel Vázquez Ruiz.

Universidad de Sonora. México 
Año 13.

Revista de Investigación

Núm. 33

Académica sin Frontera

https://revistainvestigacionacademicasinfrontera.unison.mx/index.php/RDIASF

Recibido el 17 de junio de 2020. Dictaminado mediante arbitraje favorablemente 30 de noviembre de 2020.

Dra. Lorena Vélez García.

Universidad Autónoma de Baja California. México

Dra. Pabla Peralta Miranda.

Universidad Simón Bolívar, Barranquilla, Colombia

Mtro. Roberto Espíritu Olmos

Universidad de Colima (FCA Tecomán) Colima

Dr. Héctor Priego Huertas.

Universidad de Colima (FCA Tecomán) Colima

Mtra. María Guadalupe Alvarado Ibarra.

Universidad de Sonora. México.

MSc. Celso Germán Sánchez Zayas

Universidad de Camagüey, Ignacio Agramonte Loynaz, Cuba

Dra. María Luisa Quintero Soto

Universidad Autónoma del Estado de México

Dr. Eyder Bolivar Mojica

Universidad Católica, Luis Amigó, Medellin, Colombia

Revisores de Textos en Inglés

Mtro. Renato Encinas

Mtra. Cecilia Guadalupe Martínez Solano

\section{Comité científico}

Dr. Rosendo Martínez Jiménez. Universidad Autónoma Benito Juárez de Oaxaca.

Dr. Hugo Neftalí Padilla. Universidad Estatal de Sonora

Dra. María Teresa Gaxiola Sánchez. Universidad de Sonora.

Dr. José Cesar Kaplan. Universidad Estatal de Sonora.

Dr. Alfredo Islas Rodríguez. Universidad de Sonora

Frecuencia de publicación: semestral / 2 números por año. 
Recibido el 17 de junio de 2020. Dictaminado mediante arbitraje favorablemente 30 de noviembre de 2020.

Revista de Investigación Académica sin Frontera (RIASF) con (ISSN: 2007-8870) es un interlocutor internacional de acceso abierto revisado diario en línea en el ámbito del de las Ciencias Económicas Administrativas y Sociales. Su objetivo principal es dar a los trabajos de investigación de calidad. Cubre todas las sub-campos de los campos anteriormente mencionados. Proporciona la plataforma a académicos, estudiantes y profesionales. Sólo pública trabajos de investigación y artículos de revisión inicial. Documento presentado debe cumplir con algunos criterios como, debe ser original, inédita y no estén sometidos a ninguna otra revista.

RIASF es una revista arbitrada / Revisión por pares International. Publicamos documentos sobre una variedad de temas, contextos y estrategias de análisis que examinan la relación entre la rápida evolución para la Sociedad y la tecnología del conocimiento.

REVISTA DE INVESTIGACIÓN ACADÉMICA SIN FRONTERA, Año 13, No. 33, Julio - diciembre 2020, es una publicación semestral de investigación científica, editada por la Universidad de Sonora, a través de las División de Ciencias Económicas y Sociales, de la Unidad Regional Sur, Blvd. Lázaro Cárdenas No. 100, Col. Francisco Villa, Navojoa, Sonora, Sonora, México, C.P. 85880. Tel. (642) 425- 9954.

https://revistainvestigacionacademicasinfrontera.unison.mx/index.php/RDIASF revistaacademicasinfrontera@unison.mx.

Editor responsable: Francisco Espinoza Morales. Reserva de Derechos al Uso Exclusivo: 04-2013121811323700-203 e ISSN: 2007-8870, ambos otorgados por el Instituto Nacional de Derecho de Autor. Inscrita en el Directorio de LATINDEX, con Núm. De folio 20014, folio único 14590. Responsable de la última actualización de este Número, Unidad Informática de la Universidad de Sonora, fecha de la última modificación, 30 de diciembre 2020, indexada a Cite Factor Academic Scientific Journal y Journals Master (IIJIF) y Red Latinoamericana de Revistas Académicas en Ciencias Sociales y Humanidades, (Latín Rev). Las opiniones expresadas por los autores no necesariamente reflejan la postura del editor de la publicación. Se autoriza la reproducción total o parcial de los contenidos e imágenes en la presente publicación siempre y cuando se cuente con la autorización del editor y se cite plenamente la fuente. 
Año 13.

Revista de Investigación

Núm. 33

Académica sin Frontera

ISSN: 2007-8870

https://revistainvestigacionacademicasinfrontera.unison.mx/index.php/RDIASF

Recibido el 17 de junio de 2020. Dictaminado mediante arbitraje favorablemente 30 de noviembre de 2020.

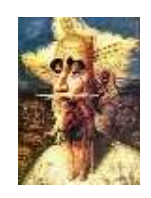

Nos complace anunciar que su diario, "Academic Research Journal Withoutborders" (ISSN/EISSN 2007-8870) fue evaluado positivamente en la indexación Citefactor, ahora la página de la revista está disponible en línea, en caso de cualquier problema.

Journals Master | International Innovative Journal Impact Factor (IIJIF)

Red Latinoamericana de revistas Académicas en Ciencias Sociales y Humanidades
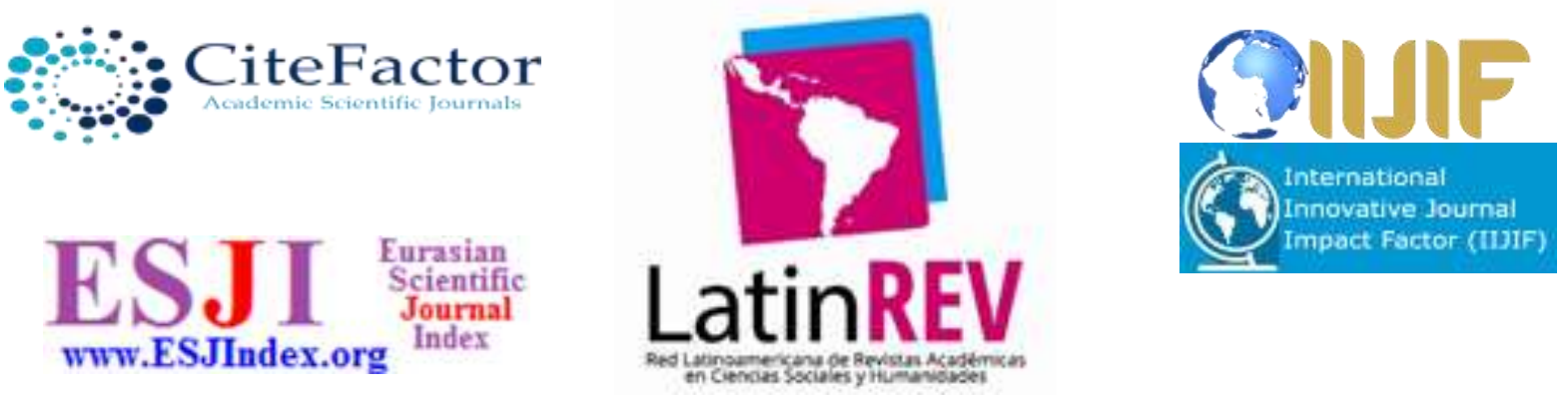

https://www.neliti.com
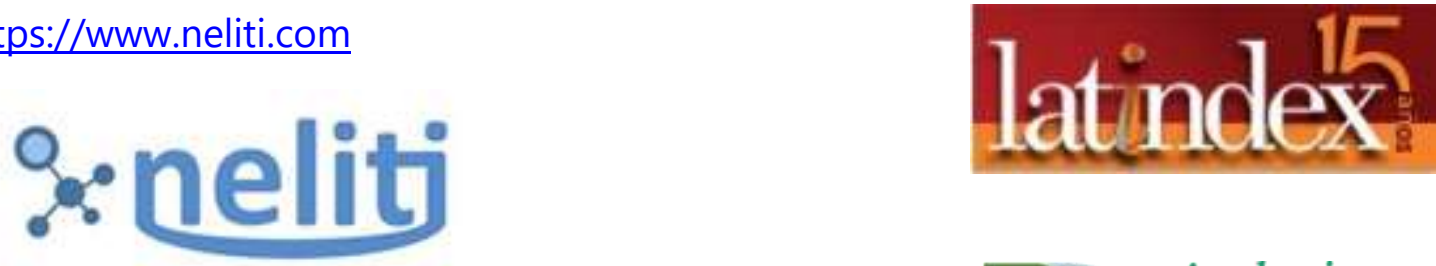

Indonesia's Research Repository

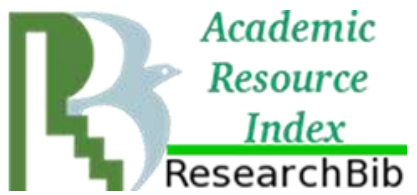

